\title{
Development of High Yielding Deep Water Rice Variety BRRI dhan91 for Semi Deep Flooded Ecosystem of Bangladesh
}

\author{
A K M Shalahuddin ${ }^{*}$, A S M Masuduzzaman², M M Emam Ahmed1, T L Aditya ${ }^{3}$ and M S Kabir ${ }^{4}$
}

\begin{abstract}
Deep water rice ecosystem represents the flood-prone rice ecosystem where rice plant requires elongation ability to reach the surface with a certain amount of plant height to withstand in stagnant flood water condition. Low yield potentiality of locally adapted deep water cultivars limits the total rice production in the country. In present study, efforts were made to evaluate the suitability and adaptability of newly developed high yielding deep water breeding line BR10230-15-27-7B and control variety Fulkori under semi deep water ecosystem of farmer's field condition in three consecutive years. At six locations, water depth varied from 60 to $140 \mathrm{~cm}$ under semi deep water ecosystem. In 2016 and 2017, mean yield of the line ranged between 2.9 to $3.1 \mathrm{t} \mathrm{ha} \mathrm{A}^{-1}$ while $_{1.7} \mathrm{t}^{-1} \mathrm{f}^{-1}$ for the local control variety Fulkori. However, around $1.0 \mathrm{t} /$ ha yield advantage was found for the newly developed breeding line. Thus, the higher yield potentiality of the breeding line under $140 \mathrm{~cm}$ water depth conditions suggested its suitability under shallow flooded environments. During final evaluation in 2018, larger variation was observed in terms of grain yield ranging from 1.1 to $3.8 \mathrm{tha}^{-1}$ for the line while 0.4 to $1.7 \mathrm{t} \mathrm{ha}^{-1}$ for the control variety when evaluated under actual deep water areas. This result also supported that this line have greater potentiality under shallow flooded condition. In addition, the breeding line exhibited similar plant height with at least six days earliness compared to the control variety. Finally, National Seed Board (NSB) approved this line as variety and designated as BRRI dhan91 for broadcast Aman (B. Aman) season. In future, this new rice variety could help the local rice growers to cultivate modern high yielding rice variety in shallow flooded environments. BRRI dhan91 also showed better performance for tallness with lodging tolerance, submergence tolerance and moderate elongation ability under shallow flooded conditions.
\end{abstract}

Key words: Deep water rice, BRRI dhan91, new rice variety

\section{INTRODUCTION}

Rice is the staple food for more than three billion people in Asia, where more than $90 \%$ of the world's rice is produced and consumed ( $\mathrm{Li}$ and $\mathrm{Xu}, 2007)$. Asian cultivated rice (Oryza sativa L.) holds a unique position among domesticated crop species in that it is both a critical staple food and the first fully sequenced crop genome. Rice is consumed as a grain almost exclusively by humans, supplying $20 \%$ of daily calories for the world population (World Rice Statistics, FAOSTAT). Deep water rice ecosystem represents the flood-prone rice ecosystem where stagnant flood water occurred in a depth usually exceeds $100 \mathrm{~cm}$ and continues for longer period of time ranging from more than 10 days to five months (Maclean et al. 2002). However, this rice required elongation ability to reach the surface, such as the one found in floating rice up to five $m$ length. Deep water rice was cultivated in the floodplains and deltas of rivers such as the Ganges and Brahmaputra of India and Bangladesh, the Irrawaddy of Myanmar, the Mekong of Vietnam and Cambodia, the Chao Phraya of Thailand, and the Niger of West Africa (Bouman et al. 2007). This rice has been classified into two types based on stature and depth of water: (i) traditional tall, and (ii) floating. Traditional tall 
cultivars are tall with long leaves and grown at water depths between 50 and $100 \mathrm{~cm}$ while floating rice is grown in $100 \mathrm{~cm}$ or deeper situations. Apparently, each of these types requires specific adaptive traits, which required the development of unique varieties (Lafitte et al. 2006).

In Bangladesh, deep water rice covers an area of 0.48 million ha where cultivation of transplant Aman rice is limited by high level of water depth throughout the growing season (BBS, 2006, Ahmed et al. 2016). In Bangladesh, most of the deep water rice is floating type where the depth of water can exceed $4 \mathrm{~m}$ (Ahmed et al. 2016). Though DWR is cultivated in small areas with low yield, attention should be given to develop high yielding deep water rice to maintain stable rice production (Ahmed et al. 2016). There are two categories of deep water areas: shallow deep and deep. Flooding depth exceeding $100 \mathrm{~cm}$ categorised as deep water and flooding depth less than $100 \mathrm{~cm}$ categorised as shallow deep flooded areas. BRRI emphasized to develop tall deep water rice varieties having submergence tolerance and moderate level of stem elongation suitable for shallow deep flooded areas.

In this regard, many advanced breeding lines of DWR have been developed by Bangladesh Rice Research Institute (BRRI) for semi-deep water ecosystem where level of water depth is relatively low. Thus, the present study was undertaken to evaluate the agronomic performances of newly developed breeding line BR10230-15-27-7B across shallow flooded ecosystem of Bangladesh.

\section{MATERIALS AND METHODS}

Plant materials. BRRI dhan91 is an outcome of a single cross between two breeding lines Tilakkachari/BRRI dhan41 with a hope to develop a semi deep water submergence tolerant rice variety in Bangladesh. The pedigree of BRRI dhan91 is BR10230-15-27-7B.
The crossing was done in 2009 and fixed line was developed through hybridization followed by modified bulk and pedigree selection. BRRI developed advanced breeding line BR10230-15-27-7B and local deep water rice variety Fulkori were used for this study.

Growing conditions of paddy fields. Field trials were performed under shallow flooded areas followed by Randomized Complete Block (RCB) design with three replications in three consecutive seasons, B. Aman 2016, 2017 and 2018. In B. Aman 2016 season, the field trials were conducted at Goainghat, Sylhet; Sibpur, Habiganj; Jatrapasha, Habiganj and Gopalganj. In B. Aman 2017 season, the field trials were conducted at Goainghat, Sylhet; Sibpur, Habiganj; Jatrapasha, Habiganj; Nagorpur, Tangail; Natore and Gopalganj. In B. Aman 2018 season, the field trials were evaluated at Bhanga, Faridpur; Moksudpur, Gopalganj; Sadar, Manikganj; Singair, Manikganj; Ghior, Manikganj; Balikhal, Habiganj; Sadar, Tangail; Homna, Cumilla and Shibbari farm, BRRI Gazipur. Land was well prepared in semi-dry conditions. Seeding was done in between first week of May to first week of June in each year. Unit plot size was $5 \times 5 \mathrm{~m}^{2}$ and spacing of 20 $\mathrm{cm}$ was maintained between two lines and continuous seed sowing was done in a line. The seed rate was $35 \mathrm{~kg} / \mathrm{ha}$ (30-40 seeds per meter line or 130-150 seeds per square meter based on seed germination percentage). For seeding, farrow was created in soil and seeds were placed in 2-2.5 cm depth and covered by soil. Fertilizers were applied @ 150, 100, 70, 60 and $10 \mathrm{~kg} / \mathrm{ha}$ Urea, TSP, MoP, Gypsum and $\mathrm{ZnSO}_{4}$ respectively. Full dose of TSP, Gypsum and $\mathrm{ZnSO}_{4}$ were applied as basal; Urea was top dressed in 2-3 split depending on flood water depth: $1^{\text {st }}$ at about 35 DAS (days after seeding), $2^{\text {nd }}$ at about 55 DAS (before flood water comes) and at $15-25 \mathrm{~cm}$ water depth condition (about 75 DAS). When flood water or stagnant water depth was more than $50 \mathrm{~cm}$, urea application was avoided. 
Evaluation of agronomic traits. Plant height, growth duration and yield were recorded in accordance with standard system. Growth duration was counted from date of seeding to $80 \%$ grain maturity date. Grain yield was estimated from 10 square meter sample plot for each replication.

Screening for submergence and elongation. Materials were raised in trays and 21-day-old seedlings were submerged in submergence tank of BRRI for 12 days. Then, water was drained out and plants were kept for recovery. After seven days of recovery, the plant was scored for submergence tolerance and elongation based on standard evaluation system of rice from 1 (best) to 9 (poor) scores.

\section{RESULTS AND DISCUSSION}

In 2016, the breeding line BR10230-15-27-7B was evaluated across four locations. In general, plant height, growth duration and yield were selected as key trait to make comparison in between the line and the control variety Fulkori (Table 1). The mean plant height was $179 \mathrm{~cm}$ for the line and $183 \mathrm{~cm}$ for the control variety. This result indicates that newly developed breeding line have similar plant height, which have higher benefit to survive in shallow flooded areas where flood water or stagnant water reaches comparatively higher water depth. Moreover, the mean growth duration was 155 days for the line and 165 days for the control variety. This result also clearly indicates that the newly developed line is 10 days earlier than the control variety. The grain yield of the line BR10230-15-27-7B was at least $1.0 \mathrm{t}$ higher compared to the control variety Fulkori for all locations. Among the locations, the highest grain yield was observed at Gopalganj with $3.4 \mathrm{t} / \mathrm{ha}$ for the line. The mean yield was $3.1 \mathrm{t} \mathrm{ha}^{-1}$ for the line and $1.7 \mathrm{t}$ $\mathrm{ha}^{-1}$ for the control variety.

In 2017, the breeding line BR10230-15-277B was evaluated across six locations (Table 2).
The mean plant height was $177 \mathrm{~cm}$ for the line and $185 \mathrm{~cm}$ for the control variety Fulkori. For growth duration, it was 153 days for the line and 168 days for the control variety. This result also clearly indicates that the newly developed line is 15 days earlier than the control variety. The grain yield of the line BR10230-15-27-7B was at least $1.0 \mathrm{t} \mathrm{ha}^{-1}$ higher compared to the control variety Fulkori for all locations. Among the locations, the highest grain yield was observed at Jatra-pasha, Habiganj with 3.4 $\mathrm{t} \mathrm{ha}^{-1}$ for the line. However, the mean yield was $2.9 \mathrm{t} \mathrm{ha}^{-1}$ for the line and $1.7 \mathrm{t} \mathrm{ha}^{-1}$ for the control variety. Additionally, water depth was recorded in this year and it varied from 60-140 $\mathrm{cm}$ among the observed locations. This result supported that newly developed line BR1023015-27-7B has potentiality to produce higher grain yield even under higher water depth.

In 2018, the breeding line BR10230-15-277B was evaluated across nine locations and two times evaluation was made by National Seed Board team in vegetative stage and reproductive stage, respectively.

Among the locations, the growth duration of the breeding line ranged from 148 to 173 days while 149 to 181 days for the control variety (Table 3 ). The mean growth duration was 156 days for the line BR10230-1527-7B and 162 days for the control variety Fulkori. This result also clearly supported the results of the previous years and the line was six days earlier than the control variety. Although, the growth duration of both line and the control variety was unexpectedly high at Homna, Cumilla due to early seeding.

Among the locations, the grain yield of the breeding line ranged from 1.1 to $3.8 \mathrm{t} \mathrm{ha}^{-1}$ while 0.4 to $1.7 \mathrm{t} \mathrm{ha}^{-1}$ for the control variety (Table 3). The mean grain yield was $2.4 \mathrm{t} \mathrm{ha}^{-1}$ for the line and $1.0 \mathrm{t} \mathrm{ha}^{-1}$ for the control variety. However, the large variation in grain yield over the evaluated locations suggested that one rice variety have different potentiality across deep water rice areas. Additionally, this variation greatly depends on available water 
depth in those particular areas in the cultivated season and one specific variety is not suitable for all the deep water areas. Thus, the evaluated line was recommended for shallow flooded areas because it showed consistency in grain yield at these conditions (Tables 1 and 2).

Furthermore, the line has moderate lodging tolerance, moderate elongation ability, strong stem, erect and long flag leaf, deep green leaves and no leaf senescence at maturity which facilitates maximum solar light uptake to give high yield (Fig. 1). Due to the presence of awn in Fulkori the grain appearance of BR10230-1527-7B was also satisfactory compared to the control variety (Fig. 2).
In B. Aman 2018 season, BR10230-15-27$7 \mathrm{~B}$ and Fulkori were given a water pressure under artificial submerged conditions (12 days) with $80 \mathrm{~cm}$ water depth to evaluate the performance in aspect of elongation ability, submergence tolerance and survivability. Fulkori showed poor performance for submergence tolerance (score 9), but showed better elongation ability (score 2). BRRI dhan91 (BR10230-15-27-7B) showed better for both submergence tolerance (score 3), as well as showed moderate elongation ability (score 3) for its best flood adaptation under shallow flooded conditions (Table 4).

Table 1. Performance of the line, BR10230-15-27-7B and the control variety, Fulkori in Broadcast Aman 2016.

\begin{tabular}{|c|c|c|c|c|c|c|c|}
\hline \multirow{2}{*}{ Designation } & \multirow{2}{*}{$\begin{array}{l}\text { Mean plant } \\
\text { height }(\mathrm{cm})\end{array}$} & \multirow{2}{*}{$\begin{array}{c}\text { Mean Growth } \\
\text { duration } \\
\text { (day) }\end{array}$} & \multicolumn{4}{|c|}{ Yield $\left(t \mathrm{ha}^{-1}\right)$ at different locations } & \multirow{2}{*}{$\begin{array}{l}\text { Mean Yield } \\
\quad\left(\mathrm{t} \mathrm{ha}^{-1}\right)\end{array}$} \\
\hline & & & L1 & L2 & L3 & $\mathrm{L} 4$ & \\
\hline BR10230-15-27-7B & 179 & 155 & 2.9 & 3.0 & 3.2 & 3.4 & 3.1 \\
\hline Fulkori & 183 & 165 & 1.8 & 1.7 & 1.9 & 1.6 & 1.7 \\
\hline
\end{tabular}

L1 = Goainghat, Sylhet $\quad$ L2= Shibpur, Habiganj $\quad$ L3 = Jatra-pasha, Habiganj L4 = Gopalganj

Table 2. Performance of the line, BR10230-15-27-7B and the control variety, Fulkori in Broadcast Aman 2017.

\begin{tabular}{|c|c|c|c|c|c|c|c|c|c|}
\hline \multirow[b]{2}{*}{ Designation } & \multirow{2}{*}{$\begin{array}{l}\text { Mean plant } \\
\text { height }(\mathrm{cm})\end{array}$} & \multirow{2}{*}{$\begin{array}{l}\text { Mean growth } \\
\text { duration (day) }\end{array}$} & \multicolumn{6}{|c|}{ Yield $\left(\mathrm{t} \mathrm{ha} \mathrm{a}^{-1}\right)$ at different locations } & \multirow{2}{*}{$\begin{array}{l}\text { Average } \\
\text { Yield }\left(\mathrm{t} \mathrm{ha}^{-1}\right)\end{array}$} \\
\hline & & & L1 & $\mathrm{L} 2$ & L3 & L4 & L5 & L6 & \\
\hline BR10230-15-27-7B & 177 & 153 & 3.2 & 2.5 & 3.4 & 2.9 & 3.1 & 2.5 & 2.9 \\
\hline Fulkori (ck) & 185 & 168 & 1.7 & 1.6 & 2.1 & 1.7 & 1.8 & 1.4 & 1.7 \\
\hline Water depth $(\mathrm{cm})$ & - & - & 60 & 65 & 90 & 120 & 140 & 130 & \\
\hline \multicolumn{10}{|c|}{$\begin{array}{l}\text { L1 = Goainghat, Sylhet, L2= Shibpur, Habiganj, L3 = Jatra-pasha, Habiganj, L4 = Nagorpur, Tangail, L5 = Natore, L6 } \\
\text { Gopalganj }\end{array}$} \\
\hline \multirow[b]{2}{*}{ Location } & \multicolumn{4}{|c|}{ BR10230-15-27-7B } & \multicolumn{5}{|c|}{ Fulkori } \\
\hline & $\begin{array}{l}\text { Growth duration } \\
\text { (days) }\end{array}$ & \multicolumn{3}{|c|}{ Grain yield ( $\left.\mathrm{t} \mathrm{ha}^{-1}\right)$} & \multicolumn{3}{|c|}{$\begin{array}{l}\text { Growth duration } \\
\text { (days) }\end{array}$} & & $\begin{array}{l}\text { Grain yield } \\
\left(\mathrm{t} \mathrm{ha}^{-1}\right)\end{array}$ \\
\hline Bhanga, Faridpur & 149 & \multicolumn{3}{|c|}{3.5} & \multicolumn{3}{|c|}{153} & & 1.3 \\
\hline Moksudpur, Gopalganj & 151 & \multicolumn{3}{|c|}{1.1} & \multicolumn{3}{|c|}{155} & & 0.4 \\
\hline Sadar, Manikganj & 150 & \multicolumn{3}{|c|}{2.2} & \multicolumn{3}{|c|}{157} & & 1.7 \\
\hline Singair, Manikganj & 152 & \multicolumn{3}{|c|}{3.8} & \multicolumn{3}{|c|}{164} & & 1.0 \\
\hline Ghior, Manikganj & 148 & \multicolumn{3}{|c|}{2.1} & \multicolumn{3}{|c|}{155} & & 1.4 \\
\hline Balikhal, Habiganj & 162 & \multicolumn{3}{|c|}{1.6} & \multicolumn{3}{|c|}{167} & & 0.6 \\
\hline Sadar, Tangail & 154 & \multicolumn{3}{|c|}{2.6} & \multicolumn{3}{|c|}{162} & & 1.2 \\
\hline Homna, Cumilla & 173 & \multicolumn{3}{|c|}{2.2} & \multicolumn{3}{|c|}{181} & & 1.1 \\
\hline BRRI Gazipur & 151 & \multicolumn{3}{|c|}{2.1} & \multicolumn{3}{|c|}{149} & & 0.7 \\
\hline Mean & 156 & \multicolumn{3}{|c|}{2.4} & \multicolumn{3}{|c|}{162} & & 1.0 \\
\hline
\end{tabular}


Table 4. Elongation ability, submergence tolerance and survival of BR10230-15-27-7B and Fulkori under artificial submerged conditions (12 days), Broadcast Aman 2018.

\begin{tabular}{lcccc}
\hline Genotype & Survival \% & $\begin{array}{c}\text { Submergence tolerance } \\
\text { score (1-9) }\end{array}$ & Stem elongation (\%) & $\begin{array}{c}\text { Elongation } \\
\text { score (1-9) }\end{array}$ \\
\hline BR10230-15-27-7B & 72 & 3 & 63 & 5 \\
Fulkori & 0 & 9 & 85 & 2 \\
\hline
\end{tabular}

Score 1 for the best and 9 for poor.

Distinguishing characters of the candidate variety BR10230-15-27-7B (BRRI dhan91) compared to the check variety Fulkori are leaf colour, flag leaf: attitude of the blade, panicle: number of the effective tillers per plant, spikelet: colour of the tip of lemma, spikelet: awns in the spikelet, leaf senescence: penultimate leaves are observed at harvest and other distinct special (Table 5). The base of the stem of BRRI dhan91 was much stronger (Fig. 1) than Fulkori Fig. 2 and it showed lodging tolerance in rainfed condition.
However, adaptability tests of the line BR10230-15-27-7B under multi-location trials in the farmers' field showed satisfactory performance in terms of grain yield in three consecutive seasons. Finally, after proper evaluation the NSB team recommended BR10230-15-27-7B as a superior genotype in respect to semi deep water tolerance for release as BRRI dhan91 in 2019. Furthermore, BRRI dhan91 could be used as a breeding material for its tallness with strong stem, submergence tolerance and moderate level of stem elongation ability.

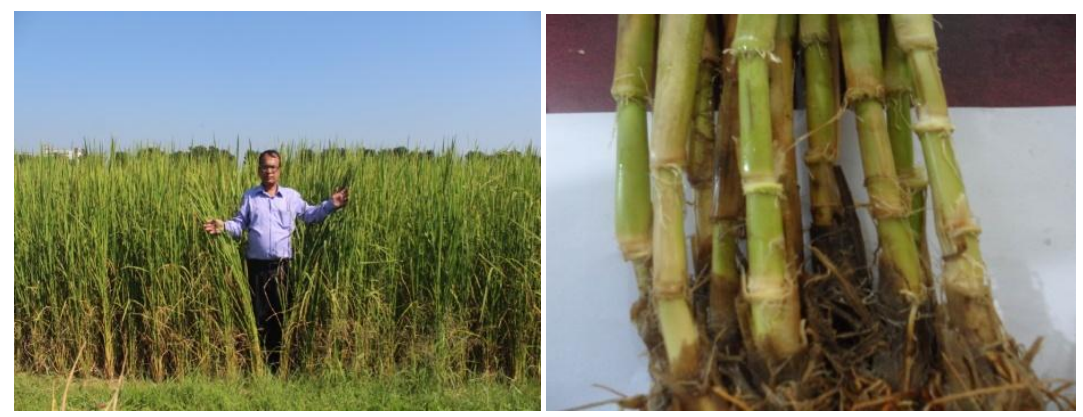

Fig. 1. BR10230-15-27-7B having tallness, strong stems and lodging tolerance

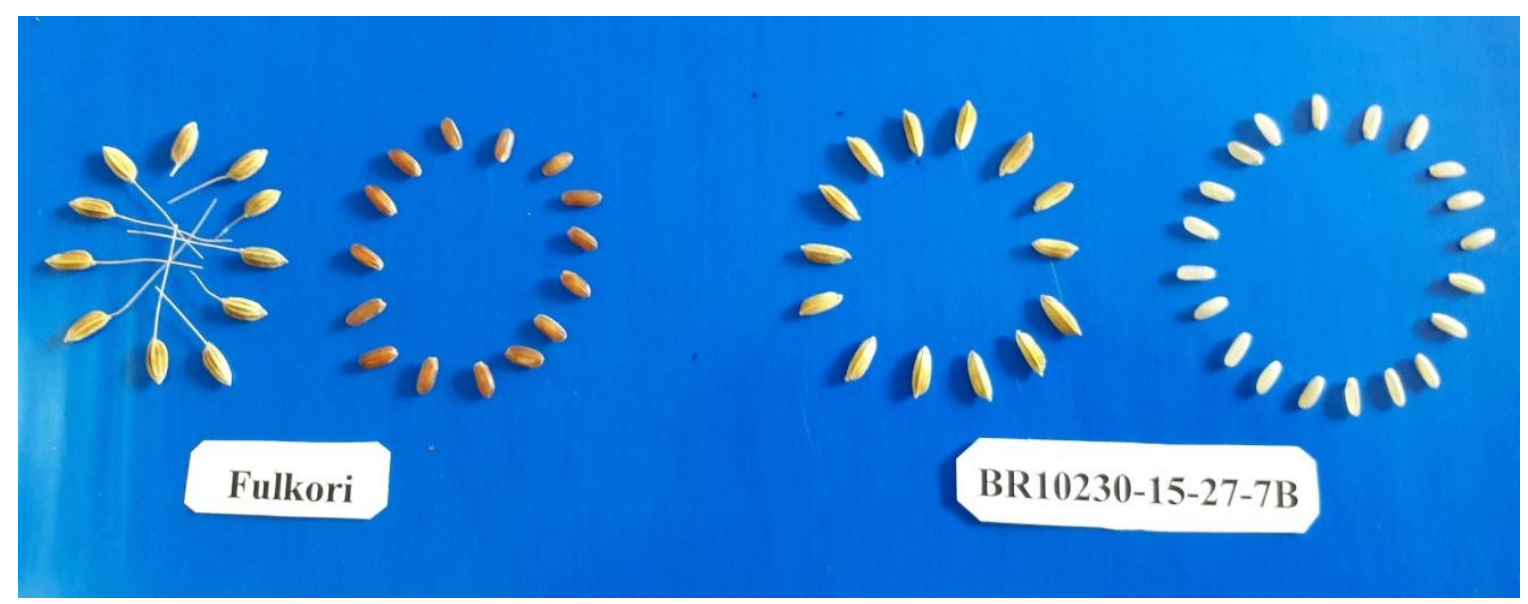

Fig. 2. Grain appearance of the local control variety Fulkori and breeding line BR10230-15-27-7B

Development of High Yielding Deep Water Rice Variety 61 
Table 5. Distinctness between BR10230-15-27-7B (BRRI dhan91) and check variety Fulkori.

\begin{tabular}{|c|c|c|c|c|c|}
\hline \multirow{2}{*}{ Characteristic } & \multicolumn{2}{|c|}{ BR10230-15-27-7B (BRRI dhan91) } & \multicolumn{2}{|c|}{ Fulkori (Check variety) } & \multirow{2}{*}{ Remark } \\
\hline & Code & State & Code & State & \\
\hline Leaf colour & 3 & Dark Green & 2 & Green & Distinct \\
\hline Flag leaf: attitude of the blade & 1 & Erect & 3 & $\begin{array}{l}\text { Intermediate or Semi- } \\
\quad \text { erect }\left(30-45^{0}\right)\end{array}$ & Distinct \\
\hline $\begin{array}{l}\text { Panicle: number of the effective } \\
\text { tillers per plant }\end{array}$ & 7 & Many & 5 & $\begin{array}{c}\text { Medium } \\
(6-10)\end{array}$ & Distinct \\
\hline $\begin{array}{l}\text { Spikelet: colour of the tip of } \\
\text { lemma }\end{array}$ & 3 & Brownish & 2 & Yellowish & Distinct \\
\hline Spikelet: awns in the spikelet & 1 & Absent & 5 & Present & Distinct \\
\hline $\begin{array}{l}\text { Leaf senescence penultimate } \\
\text { leaves are observed at harvest }\end{array}$ & 1 & Late and slow & 9 & Early and fast & Distinct \\
\hline Other distinct special (if any) & & $\begin{array}{l}\text { The base of the stem is } \\
\text { much stronger than } \\
\text { Fulkori. It has tolerance to } \\
\text { lodging with } 180 \mathrm{~cm} \\
\text { height }\end{array}$ & & $\begin{array}{l}\text { The base of the stem } \\
\text { is very weak than } \\
\text { proposed variety. It } \\
\text { might lodge in the } \\
\text { face of strong winds. }\end{array}$ & Distinct \\
\hline
\end{tabular}

At $50 \%$ heading date time, no off-type and no segregation in flowering behaviour was observed. It indicated that the candidate variety BR10230-15-27-7B is uniform according to union for the protection of New Varieties of plants (UPOV) standard. In the test plots of three consecutive years/seasons trials-no remarkable variation and segregation in respect with any traits was noted - which imply the stability of the candidate varieties.

\section{CONCLUSION}

In multi-location yield trials, performances of the breeding line BR10230-15-27-7B showed higher benefits both for growth duration and grain yield. Finally, it was released as a new rice variety as BRRI dhan91 for cultivation in shallow flooded areas based on its superior performances in NSB trials compared to control variety Fulkori. It is expected that if this variety can be cultivated in semi deep water areas of Bangladesh total rice production will be increased. In future, the new semi deep water rice variety could secure stable rice production in the country through inclusion of more areas under modern rice cultivation. BRRI dhan91 could be used in crossing programme for improvement of tallness with strong stem, submergence tolerance and moderate level of stem elongation ability.

\section{ACKNOWLEDGEMENT}

The author is thankful to technical assistance from scientists of Plant Breeding, Adaptive Research, Plant Pathology, Plant Physiology, Entomology, Grain Quality and Nutrition, Soil Science, Agronomy divisions of BRRI. DAE personnel and BRRI authorities are gratefully acknowledged for providing supports in this research activity.

\section{REFERENCES}

Ahmed, M M E; M M Haque,; A H K Robin, M A Hossain, 2016. Morphological Characterization of Deepwater Rice Genotypes. Agriculture and Food Sciences Research, 3(2): 59-65.

BBS, 'Statistical pocket book of Bangladesh,' Bangladesh Bureau of Statistics. Statistics Division, Ministry of Planning, Govt. of the People's Republic of Bangladesh. Chapter V, 2009. 
Bhuiyan, L S. 2004. Rice research and development in the flood-prone ecosystem. Int. Rice Res. Inst. p. v. ISBN 978-971-22-0197-4.

Bouman B A M, E Humphreys, T P Tuong and R Baker, 2007. Rice and water. Adv Agron. 92:187-237.

Li, Z K, and J L Xu. 2007. Breeding for drought and salt tolerant rice (Oryza sativa L.): progress and perspectives. In: Jenks M A et al (eds) Advances in molecular breeding toward drought and salt tolerant crops. Springer, USA, 531-564
Maclean, J L, D C Dawe, B Hardy and G P Hettel, 2002. Rice almanac. International Rice Research Institute, Los Banos; West Africa Rice Development Association, Bouake; International Center for Tropical Agriculture, Cali; Food and Agriculture Organization, Rome.

Lafitte, R, A Ismail, and J Bennett, 'Abiotic stress tolerance in tropical rice: Progress and the future,' Oryza, vol. 43, pp. 171-186, 2006. 
